\title{
Does the MTHFR A1298C Polymorphism Modulate the Cardiorespiratory Response to Training?
}

\author{
by \\ Paweł Cięszczyk1, Aleksandra Zarębska², Zbigniew Jastrzębski², Michał Sawczyn², \\ Izabela Kozakiewicz-Drobnik², Agata Leońska-Duniec', Mariusz Kaczmarczyk², \\ Agnieszka Maciejewska-Skrendo ${ }^{1,3}$, Piotr Żmijewski , Grzegorz Trybek4, \\ Wojciech Smótka ${ }^{5}$ Jan Pilch ${ }^{6}$,Katarzyna Leźnicka ${ }^{1}$ Ewelina Lulińska-Kuklik, \\ Marek Sawczuk ${ }^{1,2}$, Myosotis Massidda
}

The 5,10-methylenetetrahydrofolate reductase gene (MTHFR) A1298C polymorphic variant is a candidate to explain the individual differences in trainability and response to exercise training. Therefore, the aim of the study was to verify whether the A1298C polymorphism influenced the aerobic and anaerobic performance as well as body and mass composition in young Polish women following low-high impact aerobic exercise training. Two hundred and one women aged $21 \pm 1$ years (range 19-24) were included in the study. All of them completed a 12-week exercise training program and were measured for selected somatic features, aerobic capacity and cardiorespiratory fitness indices as well as peak anaerobic power and anaerobic capacity, before and after the intervention. A mixed $2 \times 2$ ANOVA for 20 dependent variables grouped in three categories was conducted. No significant interaction of the genotype with training for body mass and body composition variables was observed. Although, there were three significant genotype $x$ training interactions for maximal oxygen uptake variables, regardless of body mass i.e.: for VO2max $(p<0.05), H R \max (p<$ $0.0001)$ and HRAT/HRmax $(p<0.0001)$. Significantly greater improvement in VO2max was gained by the CC+AC group compared to the AA genotype group. The present results support the hypothesis that individual differences in trainability are at least in part determined by the genetic component and MTHFR A1298C seems to be one of the many polymorphisms involved.

Key words: MTHFR, gene polymorphism, exercise training.

\section{Introduction}

Athletic performance and response to exercise training are determined by various exoand endogenous factors (Gronek and Holdys, 2013). Analysis of heritability enabled to discover that body characteristics related to physical performance such as cardiovascular and respiratory variables, e.g., maximal oxygen uptake (VO2max), running velocity at the anaerobic threshold (VAT), cross-sectional surface area of muscles, neuromuscular coordination, as well as cardiovascular and respiratory systems' variables have strong genetic background (An et

1 - University of Szczecin, Faculty of Physical Education and Health Promotion, Szczecin, Poland.

2- Gdansk University of Physical Education and Sport, Faculty of Tourism and Recreation, Gdansk, Poland.

3 - Institute of Sport, Warsaw, Poland.

4- Department of Oral Surgery, Pomeranian Medical University, Szczecin, Poland.

5 - Clinical Department of Laryngology, School of Medicine in Katowice, Medical University of Silesia, Katowice, Poland.

6- Department of Anatomy and Antropology, Academy of Physical Education in Katowice, Poland.

7. Department of Life and Environmental Sciences, University of Cagliari, Cagliari, Italy. 
al., 2003; Missitzi et al., 2004; Stanula et al., 2014; Stunkard et al., 1990). Rapid development of molecular methods enabling the research of the structure and sequence of the human genome, and the usage of the model based on association analysis of candidate genes in sports has become feasible. To date, nearly 80 molecular markers have been reported to be correlated with physical performance, exercise and fitness as well as trainability (Ahmetov and Fedotovskaya, 2012; Ahemtov et al., 2015).

One of the candidate genes that have been recently studied in this context is MTHFR. The gene coding for 5,10-methylenetetrahydrofolate reductase (MTHFR) catalyses the irreversible reduction of 5,10-methylenetetrahydrofolate to 5methyltetrahydrofolate, the primary form of serum folate (Robien and Ulrich, 2003). MTHFR is one of the key enzymes in the metabolism of single-carbon fragments such as purine and pyrimidine synthesis, as well as conversion of homocysteine to methionine, much of which is converted to S-adenosylmethionine (SAM), a universal donor of methyl groups (Selhub, 2002). Therefore, MTHFR is, among others, involved in DNA methylation, the process of covalent addition of a methyl group to cytosine within the context of the CpG dinucleotide (Terruzzi et al., 2011). A large body of evidence has demonstrated that the methylation of the DNA is associated with the regulation of gene expression and it has been found to be involved in inhibition of gene expression (Klose and Bird, 2006). Several polymorphic sites have been described within MTHFR, however, two of them i.e., C677T and A1298C, commonly occur and are most thoroughly explored. The C677T polymorphism has been identified by Frosst et al. (1995) and results in a cytosine to thymine substitution at nucleotide position 667 (rs1801133). In consequence, a substitution of alanine for valine in the N-terminal catalytic domain of the protein occurs. The C677T TT homozygotes have been shown to have a decreased enzymatic activity as well as significantly elevated plasma homocysteine levels when compared with the $C$ allel carriers, probably due to the termolabile MTHFR protein (Frosst et al., 1995). The 677T allele has been associated with an increased risk of cardiovascular disease and birth defects (Kluijtmans et al., 1997). A second common
MTHFR polymorphism is an adenosine to cytosine transversion at nucleotide position 1298 (A1298C, rs1801131) that results in a glutamate to alanine substitution within C-terminal, Sadenosylmethionine (SAM) regulatory domain of the protein (Weisberg et al., 1998). It has been observed that individuals with the 1298 CC genotype have approximately 60 percent specific wild-type in vitro MTHFR activity (van der Put et al., 1998). It suggests that both mutant $677 \mathrm{~T}$ and 1298C alleles of the MTHFR C677T and A1298C polymorphisms influence lower methylentetrahydrofolate reductase enzyme activity (Weisberg et al., 1998; van der Put et al., 1998). While the C677T polymorphism has been established as an important genetic determinant of elevated homocysteine (Frosst et al., 1995), the effect of the A1298C polymorphism on plasma concentrations of homocysteine remains controversial. Some studies reported an impact of A1298C on plasma homocysteine, with CC homozygotes exhibiting higher plasma concentration (Castro et al., 2003, 2004). On the other hand, the study of Friedman et al. (1999) did not yield any significant results.

Despite these discrepancies, both MTHFR genetic variants showed effects on DNA methylation status, although the impact was slightly less pronounced for the A1298C polymorphism. The 1298CC MTHFR genotype has been observed to be associated with DNA hypomethylation status (Castro et al., 2003). In this case, it could be speculated that reduced MTHFR activity that causes an accumulation of homocysteine disrupts the DNA methylation pattern by favouring the synthesis of Sadenosylhomocysteine (SAH), an inhibitor of DNA methyltransferase, and affecting the synthesis of SAM, the methyl group donor in the process of DNA methylation (Friso et al., 2005; Weinstein et al., 2006). There is growing evidence suggesting that physical training may induce changes in the methylation status of crucial genes involved in e.g. muscle function (Ehlert et al., 2013). It has been recently demonstrated that DNA hypomethylation has an impact on the exercise-induced adaptation in skeletal muscles (Barres and Zierath, 2011; Terruzzi et al., 2011). It was shown that expression of myogenic factors as well as myotube length and diameter increase when induced by the hypomethylation process. 
Moreover, when a group of elite athletes was investigated for the genetic polymorphism of genes coding for enzymes involved in the onecarbon metabolism, it was found that MTHFR A1298C, methionine synthase (MTR A2756G) and methionine synthase reductase (MTRR A66G) polymorphic sites were significantly associated with elite athlete status (Terruzzi et al., 2011).

In our previous study, we analyzed whether the functional A1298C polymorphism in the MTHFR gene was associated with athletic status (Zarebska et al., 2014b). We investigated the distribution of the A1298C variant in 1144 Polish and Russian athletes as well as in 1540 control participants. Significant differences in genotype (CC and $\mathrm{AC}$ ) and allele (C) distributions among sprint-strength/strength athletes and sedentary controls for each nationality were found. The results of the study suggest that the functional A1298C polymorphism in the MTHFR gene is associated with athletic status in Polish and Russian athletes, and the presence of the $\mathrm{C}$ allele seems to be beneficial in sprint-strength and strength athletes.

Considering the aforementioned studies and promising results of our previous analysis, we decided to verify whether the A1298C polymorphism in the MTHFR gene had influence on the aerobic and anaerobic performance as well as body and mass composition in young Polish women. To test this hypothesis, we conducted a genetic association study that aimed to detect a relationship between the A1298C polymorphism and: i) VO2max test variables, ii) Wingate test variables, and iii) body composition measurements. Therefore, we examined the allele and genotype distribution of the MTHFR A1298C polymorphism in a group of Polish women; furthermore, we measured the changes of VO2max test variables, Wingate test variables and body composition measurements before and after the completion of a 12-week training program to verify whether there was an interaction between the genotype and training.

\section{Material and Methods}

\section{Ethics Statement}

All the procedures followed in the study were approved by the Ethics Committee of the Regional Medical Chamber in Szczecin (Approval number 09/KB/IV/2011) and were conducted according to the principles of the World Medical Association Declaration of Helsinki and ethical standards in sport and exercise science research.

\section{Participants}

Two hundred and one Polish Caucasian women aged $21 \pm 1$ years (range 19-24) met the inclusion criteria and were included in the study. None of these individuals had engaged in regular physical activity in the previous 6 months. They had no history of any metabolic or cardiovascular diseases. Participants were nonsmokers and refrained from taking any medications or supplements known to affect the metabolism. Participants had no muscle imbalances, which could influence their fitness performance (Stastny et al., 2016). Three weeks before the beginning of intervention and during the training period, participants were asked to keep a balanced diet of approximately 2000 kilocalories per day.

\section{Training Protocol}

The training period was preceded by a week-long familiarization stage, when the examined women exercised 3 times a week for 30 min, at an intensity of about $50 \%$ of their maximal heart rate $\left(\mathrm{HR}_{\max }\right)$. After the week-long familiarization stage, proper training started. Each training unit consisted of a warm-up routine (10 $\mathrm{min})$, the main aerobic routine $(43 \mathrm{~min})$, and stretching and breathing exercise $(7 \mathrm{~min})$. The main aerobic routine was a combination of two alternating styles i.e. low and high impact. A low impact style comprised movements with at least one foot on the floor at all times, whereas a high impact style included running, hopping and jumping with a variety of flight phases (de Angelis et al., 1998). A 12-week program of lowhigh impact aerobics was divided as follows: (i) 3 weeks including 9 training units, 60 min each, at about $50-60 \%$ of HRmax, tempo 135-140 bpm, (ii) 3 weeks comprising 9 training units, 60 min each, at

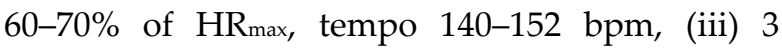
weeks including 9 training units, $60 \mathrm{~min}$ with an intensity of $65-75 \%$ of $\mathrm{HR}_{\max }$, tempo $145-158$ bpm, and (iv) 3 weeks comprising 9 training units, 60 min with an intensity of $65 \%-80 \%$ of $\mathrm{HR}_{\max }$, tempo 145-160 bpm. All 36 training units were administered and supervised by the same instructor.

\section{Body Composition Measurements}

All participants were measured for selected body mass and body composition 
variables before and after the completion of a 12week training period, which had been shown appropriate to observe changes in body composition (Lehnert et al., 2015; Mikołajec et al., 2013). Body mass and body composition were assessed by bioimpedance analysis (body's inherent resistance to the electrical current) with the use of an electronic scale (Tanita TBF 300M). The device analysed body composition based on the differences of the ability to conduct the electrical current by body tissues (different resistance) due to different water content. Body mass and body composition measurements taken with the use of the electronic scale were as follows: total body mass $(\mathrm{kg})$, fat freemass (FFM, $\mathrm{kg})$, fat mass $(\mathrm{kg})$, fat mass percentage $(\% \mathrm{FM})$, body mass index $($ BMI $=$ body mass $(\mathrm{kg}) \times$ body height $\left.\left(\mathrm{m}^{2}\right)^{-1}\right)$, total body water (TBW, $\mathrm{kg}$ ).

Aerobic capacity test $\left(\mathrm{VO}_{2 \max }\right)$

Subjects performed a continuous graded exercise test on an electronically braked cycle ergometer (VIAsprint ${ }^{\mathrm{TM}}$ 150P Bicycle, CareFusion Germany $\mathrm{GmbH}$, Hoechberg, Germany) with an automatically calibrated volume sensor and a breath-by-breath gas analyzer (Oxycon Pro, Erich JAEGER GmbH, Hoechberg, Germany) to determine their maximal oxygen uptake $\left(\mathrm{VO}_{2 \mathrm{max}}\right)$, $H_{\text {max, }}$ maximal peak respiratory minute volume (VEmax), before and after the completion of a 12week training period. The device was calibrated in accordance with the manufacturer's instructions. A previously implemented protocol was used to determine $\mathrm{VO}_{2 \max }$ (Zarebska et al., 2014a). The test began by $5 \mathrm{~min}$ continuous pedaling, with a frequency of 60 revolutions per minute (RPM) and a relative load of $1.2 \mathrm{~W} / \mathrm{kg}$. After this phase, the workload was systematically increased by 15 watts every minute until voluntary exhaustion. The effort was interrupted when pedaling frequency declined by $10 \%$, that is, when the pedalling frequency fell below 54 RPM. All of the participants reached RER greater than 1.0. The highest values of oxygen uptake, heart rate, minute ventilation and power output maintained for $15 \mathrm{~s}$ were considered to be $\mathrm{VO}_{2 \max }$, $H_{\text {max }}, V_{\text {max }}$ and $P_{\max }$, respectively. The anaerobic threshold (AT) values were obtained using the Vslope method (Beaver et al., 1986). Briefly, after measuring participant's $\mathrm{VO}_{2 \max }$ and $\mathrm{VCO}_{2 \max }$ a plot of changes of $\mathrm{VCO}_{2 \max }$ as a function of $\mathrm{VO}_{2 \max }$ was generated. The point, where the change in the slopes occurred because of increased $\mathrm{CO}_{2}$ production connected with lactate accumulation was identified as $\mathrm{VO}_{2} / \mathrm{AT}$ value.

\section{The Wingate anaerobic test}

A 30-s Wingate test on a cycle ergometer (Monark Ergomedic 894 E, Monark, Sweden) was used to assess peak power and total work before and after the completion of the 12-week training period. A relative load corresponding to $7.5 \%$ of the subject's body mass was applied (Czuba et al., 2013; Lehnert et al., 2015). Before performing the test, the participants completed a 10-min warmup, including pedaling at a frequency of $60 \mathrm{RPM}$, with a relative load of $1.2 \mathrm{~W} / \mathrm{kg}$ and three rapid accelerations between the 7th and 10th minute (Petr et al., 2014). After the warm-up, the subjects performed stretching and relaxing exercises for 5 min and then started the test (Bar-Or, 1987).

\section{Genetic Analyses}

The buccal cells donated by the subjects were collected in Resuspension Solution (GenElute Mammalian Genomic DNA Miniprep Kit, Sigma, Germany) with the use of sterile foamtipped applicators (Puritan, USA). DNA was extracted from the buccal cells using a GenElute Mammalian Genomic DNA Miniprep Kit (Sigma, Germany) according to the manufacturer's protocol. All samples were genotyped in duplicate using an allelic discrimination assay on a StepOne Real-Time Polymerase Chain Reaction (RT-PCR) instrument (Applied Biosystems, USA) as previously described (Zarebska et al., 2014).

\section{Statistical Analyses}

Allele frequencies were determined by gene counting. To test the influence of the MTHFR A1298C polymorphism on training response, $2 \times 2$ mixed-design ANOVA was used. Additionally, the Kolmogorov-Smirnov test was used to check for data normality, and the post hoc Tukey test was applied when interaction was significant and used to perform pair-wise comparisons. The level of statistical significance was set at $p<0.05$.

\section{Results}

Genotypes were determined for all 201 DNA samples of participants - genotyping error was assessed as $0 \%$, while the call rate (the proportion of samples in which genotyping provided unambiguous reading) was $100 \%$.

In order to examine a hypothesis that the MTHFR polymorphism modulates aerobic 
training response, we conducted a mixed $2 \times 2$ ANOVA with one between-subject (MTHFR genotype: $\mathrm{CC}+\mathrm{AC}$ vs $\mathrm{AA}$ ) and one within-subject factor (time: before vs after aerobic training) for 20 dependent variables grouped in three categories (Tables 1-3). Sixteen significant main effects of performed training were identified: i) body mass and body composition measurements, ii) maximal oxygen uptake variables, as well as, iii) Wingate test variables. Only four variables analyzed did not improve following training: $\mathrm{FFM}\left(\mathrm{F}_{(1,199)}=2.72\right.$, $p=0.100$, Table 1), TBW $\left(\mathrm{F}_{(1,199)}=1.30, p=0.255\right.$, Table 1), $\mathrm{VO}_{2} \mathrm{AT} / \mathrm{VO}_{2 \max }\left(\mathrm{F}_{(1,199)}=1.84, p=0.177\right.$,
Table 2$)$ and HR/AT $\left(\mathrm{F}_{(1,199)}=3.00, p=0.083\right.$, Table 2).

There was no significant interaction of the genotype with training for body mass and body composition variables (Table 1.). There were three significant genotype $\mathrm{x}$ training interactions for maximal oxygen uptake variables, i.e.: for absolute $\mathrm{VO}_{2 \max }\left(\mathrm{F}_{(1,199)}=4.9, p=0.024\right)$ and $\mathrm{VO}_{2 \max }$ per body mass $\left(\mathrm{F}_{(1,199)}=4.93, p=0.027\right), \mathrm{HR}_{\max }$ $\left(\mathrm{F}_{(1,199)}=31.3, p<0.0001\right)$ and $\mathrm{HRAT}_{\mathrm{AT}} / \mathrm{HR}_{\max }\left(\mathrm{F}_{(1,199)}=\right.$ 21.1, $p<0.0001$ ) (Table 2). There was no interaction effect between the genotype and training for Wingate test variables (Table 3).

\begin{tabular}{|c|c|c|c|c|c|c|c|}
\hline \multicolumn{8}{|c|}{$\begin{array}{c}\text { Table } \mathbf{1} \\
\text { MTHFR genotypes and body mass and body composition variables before and after training } \\
(\text { two-way mixed ANOVA) }\end{array}$} \\
\hline \multirow[b]{2}{*}{ Variable } & \multicolumn{2}{|c|}{$C C+A C(n=120)$} & \multicolumn{2}{|c|}{$\mathrm{AA}(\mathrm{n}=81)$} & \multirow[b]{2}{*}{ Genotype } & \multirow[b]{2}{*}{ Training } & \multirow{2}{*}{$\begin{array}{c}\text { Genotype } x \\
\text { Training }\end{array}$} \\
\hline & $\begin{array}{l}\text { Before } \\
\text { training }\end{array}$ & $\begin{array}{c}\text { After } \\
\text { training }\end{array}$ & $\begin{array}{l}\text { Before } \\
\text { training }\end{array}$ & $\begin{array}{c}\text { After } \\
\text { training }\end{array}$ & & & \\
\hline $\begin{array}{l}\mathrm{BM} \\
(\mathrm{kg})\end{array}$ & $61.0 \pm 6.1$ & $60.4 \pm 6.3$ & $59.2 \pm 6.8$ & $58.8 \pm 6.7$ & $p=0.064$ & $p<0.0001$ & $p=0.511$ \\
\hline 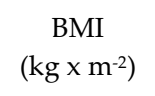 & $21.8 \pm 2.5$ & $21.6 \pm 2.5$ & $21.4 \pm 2.5$ & $21.3 \pm 2.3$ & $p=0.267$ & $p<0.0001$ & $p=0.357$ \\
\hline BMR (kJ) & $6074 \pm 262$ & $6054 \pm 271$ & $5999 \pm 285$ & $5975 \pm 283$ & $p=0.052$ & $p<0.0001$ & $p=0.569$ \\
\hline $\begin{array}{l}\text { Tissue } \\
\text { impedance } \\
(\mathrm{Ohm})\end{array}$ & $551 \pm 65$ & $544 \pm 61$ & $560 \pm 51$ & $552 \pm 53$ & $p=0.301$ & $p=0.002$ & $p=0.694$ \\
\hline $\begin{array}{l}\text { Fat mass } \\
\text { percentage } \\
\quad(\%)\end{array}$ & $24.7 \pm 4.9$ & $23.8 \pm 5.0$ & $23.7 \pm 5.0$ & $22.8 \pm 5.3$ & $p=0.168$ & $p<0.0001$ & $p=0.972$ \\
\hline $\begin{array}{c}\text { Fat mass } \\
(\mathrm{kg})\end{array}$ & $15.3 \pm 4.3$ & $14.6 \pm 4.4$ & $14.3 \pm 4.6$ & $13.7 \pm 4.8$ & $p=0.138$ & $p<0.0001$ & $p=0.971$ \\
\hline FFM (kg) & $45.7 \pm 2.4$ & $45.8 \pm 2.4$ & $45.0 \pm 2.7$ & $45.1 \pm 2.7$ & $p=0.049$ & $p=0.100$ & $p=0.989$ \\
\hline TBW (kg) & $33.4 \pm 1.7$ & $33.5 \pm 1.7$ & $32.9 \pm 2.0$ & $33.0 \pm 2.0$ & $p=0.041$ & $p=0.255$ & $p=0.734$ \\
\hline
\end{tabular}

Values of the variables of both groups before and after training are means $( \pm S D) ;{ }^{*} p$ value 0.05; BM - body mass; BMI - body mass index; BMR - basal metabolic rate; FFM - free fat mass; TBW - total body water 


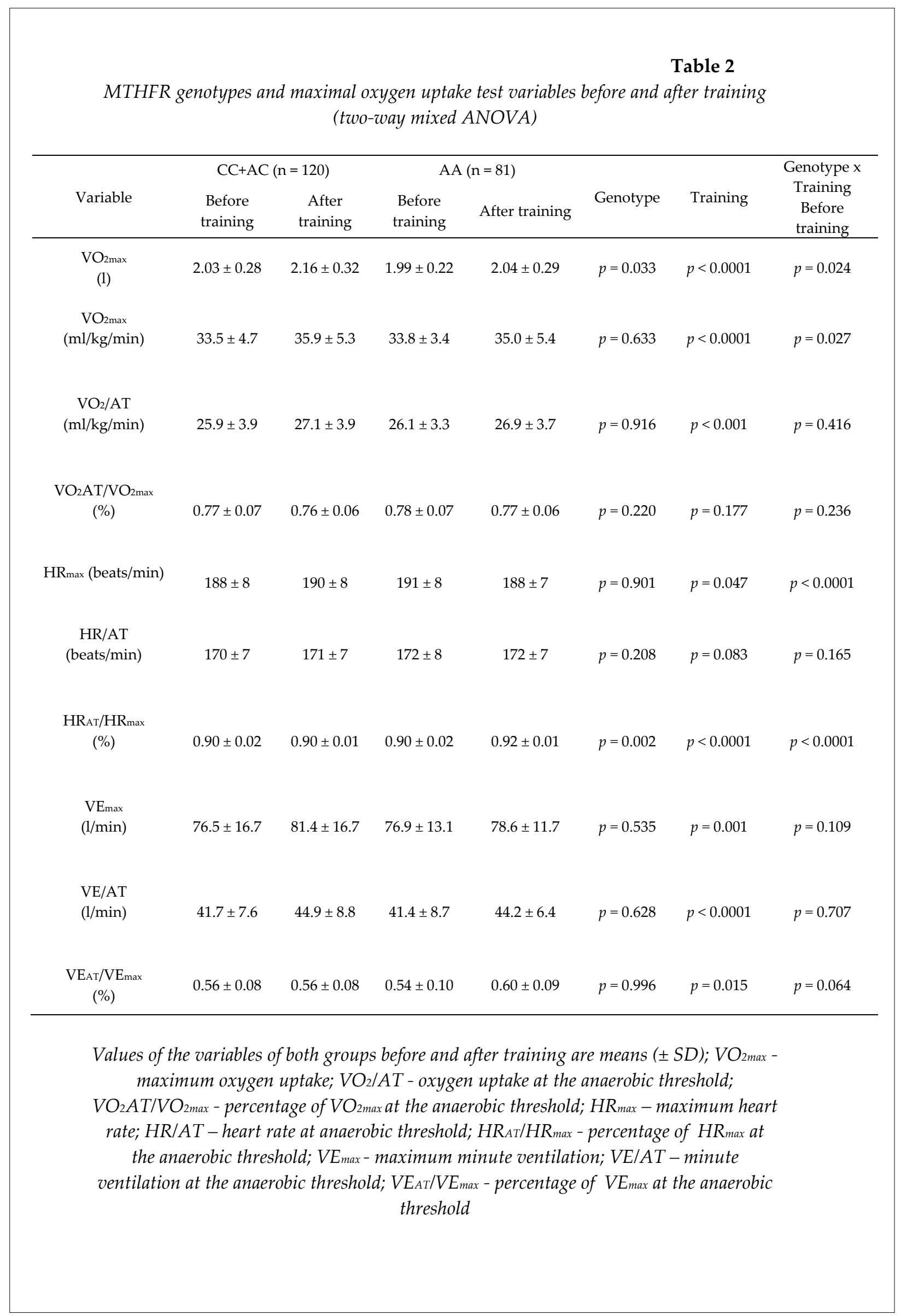


Table 3

MTHFR genotypes and Wingate test parameters before and after training (two-way mixed ANOVA)

\begin{tabular}{|c|c|c|c|c|c|c|c|}
\hline \multirow[b]{2}{*}{ Variable } & \multicolumn{2}{|c|}{$\mathrm{CC}+\mathrm{AC}(\mathrm{n}=120)$} & \multicolumn{2}{|c|}{$\mathrm{AA}(\mathrm{n}=81)$} & \multirow[b]{2}{*}{ Genotype } & \multirow[b]{2}{*}{ Training } & \multirow{2}{*}{$\begin{array}{c}\text { Genotype } \\
x \\
\text { Training }\end{array}$} \\
\hline & $\begin{array}{c}\text { Before } \\
\text { training }\end{array}$ & $\begin{array}{c}\text { After } \\
\text { training }\end{array}$ & $\begin{array}{c}\text { Before } \\
\text { training }\end{array}$ & $\begin{array}{c}\text { After } \\
\text { training }\end{array}$ & & & \\
\hline $\begin{array}{l}P_{\max } \\
(W)\end{array}$ & $464 \pm 67$ & $467 \pm 65$ & $453 \pm 67$ & $454 \pm 61$ & $p=0.186$ & $p=0.433$ & $p=0.717$ \\
\hline $\begin{array}{l}P_{\max } \\
(\mathrm{W} / \mathrm{kg})\end{array}$ & $7.62 \pm 0.88$ & $7.73 \pm 0.74$ & $7.66 \pm 0.81$ & $7.74 \pm 0.75$ & $p=0.808$ & $p=0.021$ & $p=0.718$ \\
\hline $\begin{array}{l}W_{\text {tot }} \\
(\mathrm{J} / \mathrm{kg})\end{array}$ & $178 \pm 18$ & $186 \pm 15$ & $181 \pm 18$ & $191 \pm 18$ & $p=0.147$ & $p<0.0001$ & $p=0.311$ \\
\hline
\end{tabular}

Values of the variables of both groups before and after training are means $( \pm S D) ; P_{\max }-$ maximal power; $W_{\text {tot }}$ - total work output

\section{Discussion}

The present study aimed to test whether the A1298C polymorphism in the MTHFR gene had influence on aerobic and anaerobic performance as well as body and mass composition in 201 young Polish women after the completion of a 12-week training program.

We identified 16 significant main effects of performed training on body mass and body composition measurements, maximal oxygen uptake variables, and anaerobic exercise performance variables. However, with reference to interactions between the genotype and training, only significant effects of MTHFR genotypes on VO2max variables were observed (for absolute and relative maximum oxygen uptake, maximum heart rate and percentage of maximum heart rate at the anaerobic threshold).

Our study showed that C allele carriers increased significantly their maximum oxygen uptake after the completion of a 12-week training program when compared to AA homozygotes, regardless of changes in body mass. The lack of significant changes of HRAT/HRmax in the group $\mathrm{CC}+\mathrm{AC}$ also suggests that the examined group reacted more to the training loads obtaining energy from anaerobic sources which resulted in non-significant changes expressed in percentages.
The AA genotype group obtained the energy needed to perform the same effort from aerobic transformation to a greater extent than the $\mathrm{CC}+\mathrm{AC}$ genotype group, which caused the anaerobic threshold shift for the HR in the direction of higher values, while reducing the maximum heart rate. A significant increase in VO2max, while reducing the maximum heart rate and an increase of HRAT/HRmax is a common physiological response to loads such as aerobic energy transformation carried out at and below the anaerobic threshold. Furthermore, analyzing the obtained results it can be concluded that both the $\mathrm{C}$ allele carriers and AA group reacted properly in terms of exercise physiology to the prescribed training load, improving the results aiming at adaptation to efforts of aerobic exercise, therefore increasing cardiovascular capacity.

As it has been previously stated, the MTHFR gene encodes 5,10methylenetetrahydrofolate reductase, one of the crucial enzymes in the single-carbon fragments metabolism i.e. conversion of homocysteine to methionine. The C677T TT as well as A1298C CC homozygotes have been shown to have a decreased enzymatic activity as well as significantly elevated plasma homocysteine levels (Castro et al., 2003, 2004; Frosst et al., 1995). Other studies that have analyzed 5,10- 
methylenetetrahydrofolate reductase activity found that individuals analyzed for both C677T and A1298C polymorphisms had lowered enzyme activity, but only when 677 CT and 1298 AC heterozygous genotypes occurred (Weisberg et al., 1998; van der Put et al., 1998). There are strong indications that MTHFR is involved in DNA methylation because it is a critical enzyme in the metabolism of homocysteine and methionine - the latter is a universal donor of methyl groups (Selhub, 2002). Indeed, it has been shown that both MTHFR C677T and A1298C polymorphic sites showed effects on DNA methylation status. With respect to the A1298C variant, it has been observed that the 1298CC MTHFR genotype is associated with DNA hypomethylation status (Friso et al., 2005; Weinstein et al., 2006). Investigation by Terruzzi et al. (2011) aimed to analyze elite athletes for 7 polymorphic variants in 5 genes (including MTHFR A1298C variant) involved in the one-carbon metabolism as well as to check whether DNA hypomethylation would increase the expression of muscle specific genes. The study revealed that elite athletes possessed DNA polymorphisms of DNA methylation cycle enzymes that might predispose them to quicker DNA hypomethylation and, in consequence, increased speed of entry into $S$ phase, and then DNA synthesis. With respect to the MTHFR A1298C gene variant, the over-representation of the $\mathrm{C}$ allele associated with decreased DNA methylation was found in athletes. Therefore, it was suggested that the exercise-induced demethylation in athletes was easier and more rapid, thereby resulting in increased gene expression of factors that determined proliferation and differentiation of myoblasts, what in consequence promoted muscle growth (Terruzzi et al., 2011).

Our study revealed that $C$ allel carriers were more prone to increase their maximum oxygen uptake after completion of the 12-week training program than the AA homozygotes. In view of the above mentioned facts, it might be speculated that the $\mathrm{CC}+\mathrm{AC}$ group benefited from carrying the C allele of the MTHFR A1298C polymorphism probably due to quicker DNA hypomethylation and a higher rate of DNA synthesis, what in consequence increased expression of critical genes involved in proliferation and differentiation of myoblasts as well as mitochondrial biogenesis.

Several studies have reported the role of DNA methylation in a tissue-specific gene expression during development (Geiman and Muegge, 2010; Song et al., 2009). It has also been demonstrated that hypomethylation modulates muscle differentiation and growth (Scarpa et al., 1996). Particularly, myogenic transcription factors are known to be involved in the myogenic differentiation and in the induction of musclespecific genes expression. In vitro studies in the immortalized cell line derived from satellite cells have shown that hypomethylation increases the expression of myogenic regulatory factors during the early (Myf-5 and MyoD), intermediate (Myf6), and late phase (MHC) of myogenesis. Both Myf-5 and MyoD are required for myogenic determination, as well as Myf- 6 which plays a role in terminal differentiation inducing an increment in the MHC muscle-specific gene expression (Terruzzi et al., 2011). Regular endurance aerobic exercise influences mitochondrial biogenesis by increasing mitochondrial content and volume which in consequence improves oxidative capacity (Irrcher et al., 2003). It has been shown that mitochondrial biogenesis is regulated by many transcription factors and their co-activators (Coffey and Hawley, 2007). Mitochondrial biogenesis is regulated by energy sensors such as protein kinase A (PKA), cAMP response elementbinding protein (CREB), 5' adenosine monophosphate-activated protein kinase (AMPK) and sirutin (SIRT1) that activate peroxisome proliferator-activated receptor $\gamma$ coactivator $1 \alpha$ (PGC1 $\alpha$ ). The latter induces the downstream targets (i.e. nuclear respiratory factors NRF1, NRF2 and Tfam) what results in upregulation of mitochondrial biogenesis and activity (Nunnari and Suomalainen, 2012). Epigenetic studies have suggested that the expression of PGC1 $\alpha$ may be controlled at the level of DNA methylation of PPARGC1A promoter and exercise changes DNA methylation of the promoter of PPARGC1A to favor gene expression responsible for mitochondrial biogenesis and function (Gemma et al., 2009; Sookoian et al., 2010). Recently, the study by Barrès et al. (2012) reported that upregulation of PGC- $1 \alpha$ was associated with dynamic change in DNA methylation in skeletal muscle.

The present study has several limitations that should be mentioned. Obtained results were 
received during genetic association studies and need to be interpreted with caution as they could be influenced by many factors. We observed that C-allel carries were better responders to the 12week aerobic training program in terms of higher maximum oxygen uptake. However, it is unclear whether and to what extent the effect was due to changes in DNA methylation, because in this study we did not directly measure the methylation status of the participants. As far as we know, DNA methylation is a complex process that needs a variety of accessory proteins and modifying enzymes in establishing and maintaining these chemical modifications to DNA (Voisin et al., 2015). Therefore, other genes and their polymorphic variants of proteins that are directly engaged in DNA methylation such as DNA methyltransferases (DNMTs), ten-eleven translocation (TET) proteins as well as the methionine synthase (MS) methionine synthase reductase (MSR), cystathionine-synthase (CBS) and betaine-homocysteine methyltransferase (BHMT) are of potential interest (Liyanage et al., 2014; Terruzzi et al., 2011). It might be suspected that due to a polygenic character of $\mathrm{VO} 2 \mathrm{max}$, only a small part of the total variance of this trait could be explained by the MTHFR A1298C polymorphism. Moreover, methylation marks can be modified not only by exercise, but also other environmental factors such as exposure to toxic chemicals (i.e. heavy metals, antiandrogenic toxins) and nutrition (folic acid suplementation or restriction) (Barres and Zierath, 2011; Ehlert et al., 2013). Finally, DNA methylation does not solely control the exercise-induced gene expression, as the complex transduction network with numerous signaling pathways is regulated at different molecular levels (Barres et al., 2012; Coffey and Hawley, 2007).

In conclusion, it was observed that, as a result of training, significantly greater improvement in $\mathrm{VO} 2 \mathrm{max}$ was gained by the $\mathrm{CC}+\mathrm{AC}$ group compared to the AA genotype group. The results support the hypothesis that individual differences in trainability are at least in part determined by the genetic component and MTHFR A1298C seems to be one of the many polymorphisms involved.

\section{Acknowledgements}

The study was supported by the National Science Centre (grant no. 2012/07/B/NZ7/01155).

\section{References}

Ahmetov II, Fedotovskaya ON. Sports genomics: Current state of knowledge and future directions. Cell Mol Exerc Physiol, 2012; 1(1): e1

Ahmetov I, Kulemin N, Popov D, Naumov V, Akimov E, Bravy Y, Egorova E, Galeeva A, Generozov E, Kostryukova E, Larin A, Mustafina L, Ospanova E, Pavlenko A, Starnes L, Żmijewski P, Alexeev D, Vinogradova O, Govorun V. Genome-wide association study identifies three novel genetic markers associated with elite endurance performance. Biol Sport, 2015; 32: 3-9

An P, Pérusse L, Rankinen T, Borecki IB, Gagnon J, Leon AS, Skinner JS, Wilmore JH, Bouchard C, Rao DC. Familial aggregation of exercise heart rate and blood pressure in response to 20 weeks of endurance training: the HERITAGE family study. Int J Sports Med, 2003; 24: 57-62

Bar-Or O. The Wingate anaerobic test. An update on methodology, reliability and validity. Sports Med, 1987; 4: 381-394

Barres R, Yan J, Egan B, Treebak JT, Rasmussen M, Fritz T, Caidahl K, Krook A, O'Gorman DJ, Zierath JR. Acute exercise remodels promoter methylation in human skeletal muscle. Cell Metab, 2012; 15: 405-411

Barres R, Zierath JR. DNA methylation in metabolic disorders. Am J Clin Nutr, 2011; 93: 897S-900

Beaver WL, Wasserman K, Whipp BJ. A new method for detecting anaerobic threshold by gas exchange. J Appl Physiol, 1986; 60: 2020-2027

Castro R, Rivera I, Ravasco P, Camilo ME, Jakobs C, Blom HJ, de Almeida IT. 5,10methylenetetrahydrofolate reductase (MTHFR) $677 \mathrm{C} \rightarrow \mathrm{T}$ and 1298A $\rightarrow \mathrm{C}$ mutations are associated with 
DNA hypomethylation. J Med Genet, 2004; 41: 454-458

Castro R, Rivera I, Ravasco P, Jakobs C, Blom HJ, Camilo ME, de Almeida IT. 5,10Methylenetetrahydrofolate reductase $677 \mathrm{C} \rightarrow \mathrm{T}$ and $1298 \mathrm{~A} \rightarrow \mathrm{C}$ mutations are genetic determinants of elevated homocysteine. QJM, 2003; 96: 297-303

Coffey VG, Hawley JA. The molecular bases of training adaptation. Sports Med, 2007; 37: 737-763

de Angelis M, Vinciguerra G, Gasbarri A, Pacitti C. Oxygen uptake, heart rate and blood lactate concentration during a normal training session of an aerobic dance class. Eur J Appl Physiol Occup Physiol, 1998; 78: 121-127

Czuba M, Zając A, Maszczyk A, Roczniok R, Poprzęcki S, Garbaciak W, Zając T. The Effects of High Intensity Interval Training in Normobaric Hypoxia on Aerobic Capacity in Basketball Players. J Hum Kinet. 2013; 39(1): 103-114

Ehlert T, Simon P, Moser DA. Epigenetics in sports. Sports Med, 2013; 43: 93-110

Friedman G, Goldschmidt N, Friedlander Y, Ben-Yehuda A, Selhub J, Babaey S, Mendel M, Kidron M, BarOn H. A common mutation A1298C in human methylenetetrahydrofolate reductase gene: Association with plasma total homocysteine and folate concentrations. J Nutr, 1999; 129: 1656-1661

Friso S, Girelli D, Trabetti E, Olivieri O, Guarini P, Pignatti PF, Corrocher R, Choi SW. The MTHFR 1298A>C polymorphism and genomic DNA methylation in human lymphocytes. Cancer Epidemiol Biomarkers Prev, 2005; 14: 938-943

Frosst P, Blom HJ, Milos R, Goyette P, Sheppard CA, Matthews RG, Boers GJ, den Heijer M, Kluijtmans LA, van den Heuvel LP, Rozen R. A candidate genetic risk factor for vascular disease: a common mutation in methylenetetrahydrofolate reductase. Nat Genet, 1995; 10: 111-113

Geiman TM, Muegge K. DNA methylation in early development. Mol Reprod Dev, 2010; 77: 105-113

Gemma C, Sookoian S, Alvarinas J, Garcia SI, Quintana L, Kanevsky D, González CD, Pirola CJ. Maternal pregestational BMI is associated with methylation of the PPARGC1A promoter in newborns. Obesity (Silver Spring), 2009; 17: 1032-1039

Gronek P, Holdys J. Genes and physical fitness. Trends Sport Sci, 2013; 1: 16-29

Irrcher I, Adhihetty PJ, Joseph AM, Ljubicic V, Hood DA. Regulation of mitochondrial biogenesis in muscle by endurance exercise. Sports Med, 2003; 33: 783-793

Klose RJ, Bird AP. Genomic DNA methylation: The mark and its mediators. Trends Biochem Sci, 2006; 31: 8997

Kluijtmans LA, Kastelein JJ, Lindemans J, Boers GH, Heil SG, Bruschke AV, Jukema JW, van den Heuvel LP, Trijbels FJ, Boerma GJ, Verheugt FW, Willems F, Blom HJ. Thermolabile methylenetetrahydrofolate reductase in coronary artery disease. Circulation, 1997; 96: 2573-2577

Lehnert M, Stastny P, Sigmund M, Xaverova Z, Hubnerova B, Kostrzewa M. The effect of combined machine and body weight circuit training for women on muscle strength and body composition. Journal of Physical Education and Sport, 2015; 15: 561-568

Liyanage VR, Jarmasz JS, Murugeshan N, Del Bigio MR, Rastegar M, Davie JR. DNA modifications: function and applications in normal and disease States. Biology (Basel), 2014; 3: 670-723

Mikolajec K, Maszczyk A, Zajac, T. Game Indicators Determining Sports Performance in the NBA. J Hum Kinet. 2013; 37: 145-151

Missitzi J, Geladas N, Klissouras V. Heritability in neuromuscular coordination: Implications for motor control strategies. Med Sci Sports Exerc, 2004; 36: 233-240

Nunnari J, Suomalainen A. Mitochondria: in sickness and in health. Cell, 2012; 148: 1145-1159

Petr M, Stastny P, Pecha O, Steffl M, Seda O, Kohlikova E. PPARA Intron Polymorphism Associated with Power Performance in 30-s Anaerobic Wingate Test. PloS one, 2014; 9: e107171

Robien K, Ulrich CM. 5,10-Methylenetetrahydrofolate reductase polymorphisms and leukemia risk: a HuGE 
minireview. Am J Epidemiol, 2003; 157: 571-582

Scarpa S, Lucarelli M, Palitti F, Carotti D, Strom R. Simultaneous myogenin expression and overall DNA hypomethylation promote in vitro myoblast differentiation. Cell Growth Differ, 1996; 7: 1051-1058

Selhub J. Folate, vitamin B12 and vitamin B6 and one carbon metabolism. J Nutr Health Aging, 2002; 6: 39-42

Song F, Mahmood S, Ghosh S, Liang P, Smiraglia DJ, Nagase H, Held WA. Tissue specific differentially methylated regions (TDMR): Changes in DNA methylation during development. Genomics, 2009; 93: 130-139

Sookoian S, Rosselli MS, Gemma C, Burgueno AL, Fernandez Gianotti T, Castano GO, Pirola CJ. Epigenetic regulation of insulin resistance in nonalcoholic fatty liver disease: impact of liver methylation of the peroxisome proliferator-activated receptor $\gamma$ coactivator $1 \alpha$ promoter. Hepatology, 2010; 52: 1992-2000

Stanula A, Roczniok R, Maszczyk A, Pietraszewski P, Zając A. The role of aerobic capacity in high-intensity intermittent efforts on ice-hockey. Biol Sport. 2014; 31(3): 193-199

Stastny P, Tufano JJ, Golas A, Petr M. Strengthening the Gluteus Medius Using Various Bodyweight and Resistance Exercises. Strength Cond J, 2016; 38: 91-101

Stunkard AJ, Harris JR, Pedersen NL, McClearn GE. The body-mass index of twins who have been reared apart. N Engl J Med, 1990; 322: 1483-1487

Terruzzi I, Senesi P, Montesano A, La Torre A, Alberti G, Benedini S, Caumo A, Fermo I, Luzi L. Genetic polymorphisms of the enzymes involved in DNA methylation and synthesis in elite athletes. Physiol Genomics, 2011; 43: 965-973

van der Put NM, Gabreels F, Stevens EM, Smeitink JA, Trijbels FJ, Eskes TK, van den Heuvel LP, Blom HJ. A second common mutation in the methylenetetrahydrofolate reductase gene: an additional risk factor for neural-tube defects? Am J Hum Genet, 1998; 62: 1044-1051

Weinstein SJ, Stolzenberg-Solomon R, Pietinen P, Taylor PR, Virtamo J, Albanes D. Dietary factors of onecarbon metabolism and prostate cancer risk. Am J Clin Nutr, 2006; 84: 929-935

Weisberg I, Tran P, Christensen B, Sibani S, Rozen R. A second genetic polymorphism in methylenetetrahydrofolate reductase (MTHFR) associated with decreased enzyme activity. Mol Genet Metab, 1998; 64: 169-172

Voisin S, Eynon N, Yan X, Bishop DJ. Exercise training and DNA methylation in humans. Acta Physiol (Oxf), 2015; 213: 39-59

Zarebska A, Jastrzebski Z, Kaczmarczyk M, Ficek K, Maciejewska-Karlowska A, Sawczuk M, LeońskaDuniec A, Krol P, Cieszczyk P, Zmijewski P, Eynon N. The GSTP1 c.313A>G polymorphism modulates the cardiorespiratory response to aerobic training. Biol Sport, 2014; 31: 261-266

Zarebska A, Ahmetov II, Sawczyn S, Weiner AS, Kaczmarczyk M, Ficek K, Maciejewska-Karlowska A, Sawczuk M, Leonska-Duniec A, Klocek T, Voronina EN, Boyarskikh UA, Filipenko ML, Cieszczyk P. Association of the MTHFR 1298A $>C$ (rs1801131) polymorphism with speed and strength sports in Russian and Polish athletes. J Sports Sci, 2014; 32: 375-382

\title{
Corresponding author:
}

\author{
Paweł Cięszczyk \\ University of Szczecin \\ Faculty of Physical Education and Health Promotion \\ Piastów 40 B \\ 71-065 Szczecin, Poland \\ tel.: 914442735 \\ E-mail: cieszczyk@poczta.onet.pl
}

